\title{
Identification of magnetic anomalies based on ground magnetic data analysis using multifractal modelling: a case study in Qoja-Kandi, East Azerbaijan Province, Iran
}

\author{
E. Mansouri ${ }^{1}$, F. Feizi ${ }^{2}$, and A. A. Karbalaei Ramezanali ${ }^{1}$ \\ ${ }^{1}$ Young Researchers and Elite Club, South Tehran Branch, Islamic Azad University, Tehran, Iran \\ ${ }^{2}$ Mine Engineering Department, South Tehran Branch, Islamic Azad University, Tehran, Iran
}

Correspondence to: F. Feizi (feizi.faranak@yahoo.com)

Received: 10 May 2015 - Published in Nonlin. Processes Geophys. Discuss.: 24 July 2015

Revised: 23 September 2015 - Accepted: 24 September 2015 - Published: 7 October 2015

\begin{abstract}
Ground magnetic anomaly separation using the reduction-to-the-pole (RTP) technique and the fractal concentration-area $(C-A)$ method has been applied to the Qoja-Kandi prospecting area in northwestern Iran. The geophysical survey resulting in the ground magnetic data was conducted for magnetic element exploration. Firstly, the RTP technique was applied to recognize underground magnetic anomalies. RTP anomalies were classified into different populations based on the current method. For this reason, drilling point area determination by the RTP technique was complicated for magnetic anomalies, which are in the center and north of the studied area. Next, the $C-A$ method was applied to the RTP magnetic anomalies (RTP-MA) to demonstrate magnetic susceptibility concentrations. This identification was appropriate for increasing the resolution of the drilling point area determination and decreasing the drilling risk issue, due to the economic costs of underground prospecting. In this study, the results of $C-A$ modelling on the RTP-MA are compared with 8 borehole data. The results show that there is a good correlation between anomalies derived via the $C-A$ method and the $\log$ report of boreholes. Two boreholes were drilled in magnetic susceptibility concentrations, based on multifractal modelling data analyses, between 63533.1 and 66296 nT. Drilling results showed appropriate magnetite thickness with grades greater than $20 \% \mathrm{Fe}$. The total associated with anomalies containing andesite units hosts iron mineralization.
\end{abstract}

\section{Introduction}

Mineral exploration aims at discovering new mineral deposits in a region of interest (Abedi et al., 2013). These mineral deposits could be related to magnetic anomalies which are situated within the underground. In the first step of identification underground magnetic anomalies, a few boreholes should be drilled after interpretation of ground magnetic data. Obviously, using new methods could increase the resolution of the drilling point area determination and decrease the drilling risk. A cursory look at magnetic maps would present more information about the shape of such buried features. However, the information acquired from maps can provide additional details about the specification of underground magnetic anomalies, especially exact locations. Magnetic anomaly depends on the inclination and declination of the body's magnetization generally. Also, we know that the orientation of the magnetic body depends on magnetic north. According to the mentioned issues, Baranov (1957) and Baranov and Naudy (1964) proposed a mathematical approach known as reduction-to-the-pole (RTP) for simplifying anomaly shape and determining the exact anomaly location. As a result of increasing the resolution of the RTP technique, the concentration-area $(C-A)$ fractal method was applied. Fractal geometry is a non-Euclidean geometry established by Mandelbrot (1983) and has been applied in geosciences and mineral exploration, especially in geophysical and geochemical exploration since the 1980s (Turcotte, 1989; Bolviken et al., 1992; Korvin, 1992; Cheng et al., 1994; Agterberg et al., 1996; Cheng, 1999; Turcotte, 2004; Dimri, 2005; Shen et al., 2009). 
Table 1. RTP classification of magnetic anomalies based on the fractal method.

\begin{tabular}{lll}
\hline Class ID & Class range $(\mathrm{nT})$ & Priority areas for drilling \\
\hline 1 & $45383-47424.2$ & Very low \\
2 & $47424.2-49493.7$ & Low \\
3 & $49493.7-56493.7$ & Moderate \\
4 & $56493.7-63533.1$ & High \\
5 & $63533.1-66296$ & Very high \\
\hline
\end{tabular}

In this study, the concentration-area $(C-A)$ fractal method was used to grid the RTP data set, for better classification of the RTP map, which was generated by the RTP technique. This procedure was applied to the ground magnetic data of Qoja-Kandi, Zanjan Province, Iran.

\section{The concentration-area fractal method}

The concentration-area $(C-A)$ method serves to illustrate the correlated relationship between the obtained results. Its most useful features are the easy implementation and the ability to compute quantitative anomalous thresholds (Cheng et al., 1994).

Cheng et al. (1994) proposed the concentration-area $(C-$ $A$ ) method for separating geochemical anomalies from the background in order to characterize the distribution of elemental concentrations. Equation (1) shows the general form of this model:

$A(\rho \leq \gamma) \propto \rho^{-\alpha 1} ; A(\rho \geq \gamma) \propto \rho^{-\alpha 2}$,

where $A(\rho)$ denotes the area with concentration values greater than the contour value $\rho ; v$ represents the threshold; and $\alpha_{1}$ and $\alpha_{2}$ are characteristic exponents. Pairs of estimated exponents and corresponding optimum thresholds $\left(\alpha_{1}\right.$ and $\left.\alpha_{2}\right)$ for this study are presented in Table 2. The breaks between straight line segments in the $C-A \log -\log$ plot and the corresponding values of $\rho$ are known as thresholds for separating geophysical values into different components representing different causal factors such as lithological differences, geochemical processes and mineralizing events (Lima et al., 2003). Thus, applying the $C-A$ fractal model to the geochemical data improves the resolution of the data, helping to explore the deposits. It seems that applying this model to ground magnetic data improves the accuracy of magnetite deposit exploration. The most useful feature of the $C-A$ method is its capability to compute anomaly thresholds (Goncalves et al., 2001). Using fractal theory, Cheng et al. (1994) derived similar power-law relationships and equations in extended form. The area $A(\rho)$ for a given $\rho$ is equal to the number of cells multiplied by cell area, with concentration values greater than $\rho$. Average concentration values are used for those boxes containing more than one sample. Area
Table 2. Results obtained by using the power-law method and weights of evidence procedure; $\alpha_{1}$ and $\alpha_{2}$ are the exponents of the power-law relation for concentration values less and greater than the threshold value $(v)$, respectively.

\begin{tabular}{lllll}
\hline \multirow{2}{*}{ Total magnetic intensity } & \multicolumn{3}{c}{ Power law } & \multirow{2}{*}{ W. of $T$} \\
\cline { 2 - 4 } & $v$ & $\alpha_{1}$ & $\alpha_{2}$ & $v$ \\
\hline RTP (nT) & 60022 & 0.0116 & 0.0458 & 60022 \\
\hline
\end{tabular}

concentration $A(\rho)$ with element concentrations greater than $\rho$ usually shows a power-law relation (Cheng et al., 1994).

\section{The study area and geological setting}

The Qoja-Kandi area is located within the Urumieh-Dokhtar magmatic arc in the northwest of Iran (Fig. 1). This magmatic arc is the most important exploratory area for metals, and hosts the majority of the larger metal deposits such as copper and iron (Hassan-Nezhad and Moore, 2006). The investigated area is characterized by Precambrian to Jurassic units and Oligo-Miocene volcanic rocks. Different types of metal ore deposits, such as iron, have already been documented near the studied area. The lithology of this part includes schist and shale (Kahar formation), dolomite and limestone (Elika formation), shale, sandstone and limestone (Shemshak formation), limestone, marl, sandstone, conglomerate and andesite. A magnetite dyke which has outcrops in andesite units has already been seen near the studied area. It seems that this magnetite dyke has a presence in the QojaKandi area.

\section{Ground magnetic data analysis}

Ground magnetic data are acquired in the region at $15 \mathrm{~m}$ spacing along lines in the northern direction and spaced $10 \mathrm{~m}$ apart. GSM-19T proton collected 6997 geophysical ground data. The GSM-19T proton magnetometer has an absolute accuracy of $\pm 0.2 \mathrm{nT}$.

\subsection{The TMI anomaly map}

The total-magnetic-intensity (TMI) map of the Qoja-Kandi area was obtained to delineate the subsurface anomaly. Figure 2 indicates TMI with ground magnetic data points. The ground magnetic anomalies range from 38633 to $69509 \mathrm{nT}$ and are characterized by both low and high frequencies of anomalies. The map reveals that dipolar (anomalies having positive and negative components) magnetic anomalies have a general E-W direction, which is in the centre and north of the studied area. There are three obvious dipolar magnetic anomalies (two anomalies in the east and west of the centre and one anomaly in the north) in the Qoja-Kandi prospecting 

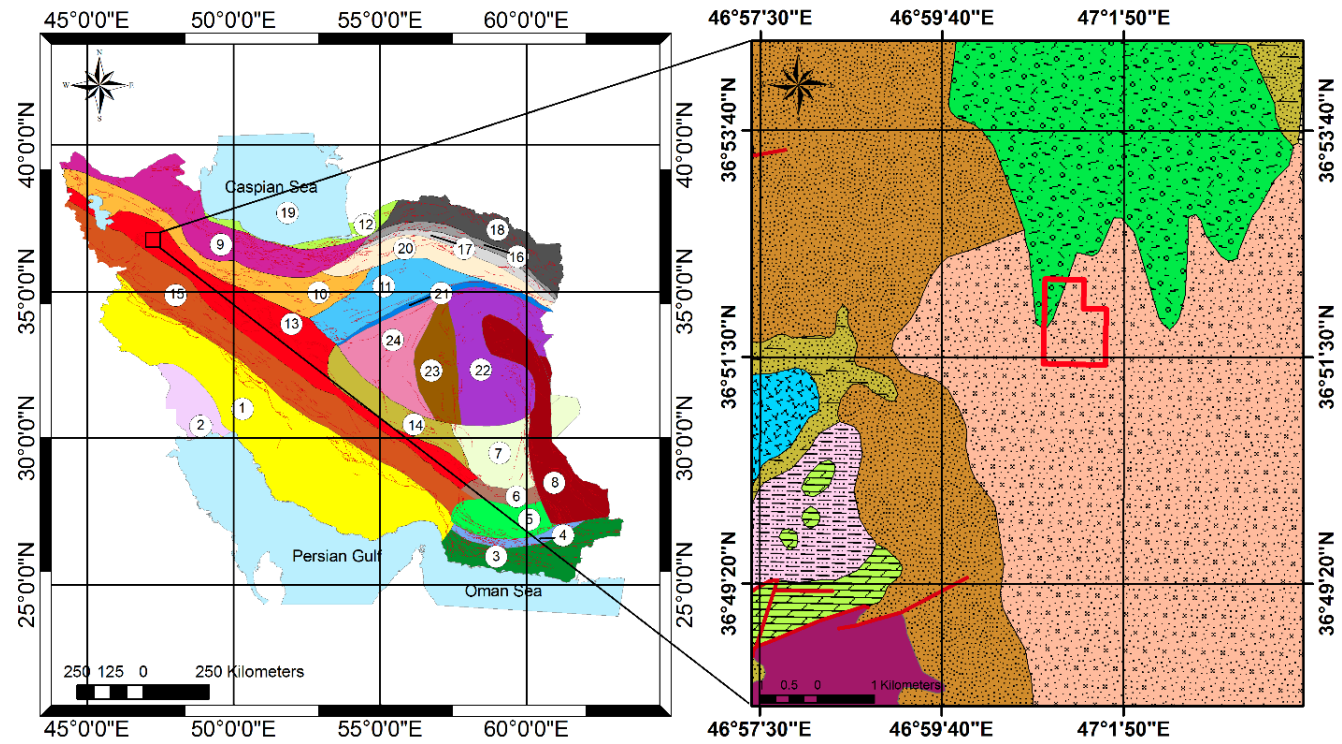

major tectonostratiographic units
1: Zagros-East Taurus hinterland,
2: Persian Gulf-Mesopotamian foreland basin,
3: Makran accretionary prism,
4: Bashagard Mountains,
5: Jazmorian- Mashkel fore arc basin,
6: Shahsavaran-Soltan magmatic arc,
7: South Lut-South Helmand back arc basin,
8: East Iran Mountain belt,
9: West- Central Alborz and lesser Caucasus hinterland,
10: Great Kavir-NorthenUrmieh lake foreland basin,
11: South Great Kavirfold and thrust belt,
12: South Caspian-Black sea foreland basin,
13: Urmieh- Dokhtar Magmatic Arc,
14: Naien-Kerman retro arc foreland basin,
15: Sanandaj-Sirjanoverthrust belts,
16: East Alborz or Binalod hinterland,
17: Torbat-e am-Neyshabour retro arc foreland basin,
18: KopetDagh hinterland,
19: South Caspian remnant basin,
20: Maiamay -Taibad Inverted back arc basin,
21: Khaf- Kavir Plain Magmatic Arc,
22: Lut Plain-Gonabad back arc basin,
23: Tabas hinterland,
24:Yazd-Khour Piggy back basin.
- Fault

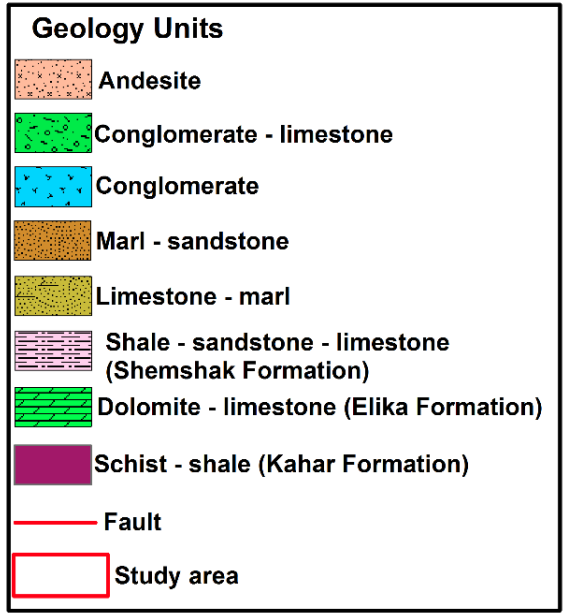

Figure 1. Physiographic-tectonic zoning map of Iran's sedimentary basins (Arian, 2013) and location of the study area.

area which are expected to depend on two magnetite dykes in andesite units.

\subsection{Reduction-to-the-pole technique}

A difficulty in interpretation with TMI anomalies is that they are dipolar (anomalies having positive and negative components) such that the shape and phase of the anomaly depends on the part of magnetic inclination and the presence of any remanent magnetization. Because of the magnetic anomaly depending on the inclination and declination of the body's magnetization, the inclination and declination of the local Earth magnetic field, and the orientation of the body with respect to magnetic north, Baranov (1957) and Baranov and
Naudy (1964) proposed a mathematical approach known as reduction to the pole for simplifying anomaly shapes.

The reduction-to-the-pole (RTP) technique transforms TMI anomalies to anomalies that would be measured if the field were vertical (assuming there is only an inducing field). This RTP transformation makes the shape of magnetic anomalies more closely related to the spatial location of the source structure and makes the magnetic anomaly easier to interpret, as anomaly maxima will be located centrally over the body (provided there is no remanent magnetization present). Thus, the RTP reduces the effect of the Earth's ambient magnetic field and provides a more accurate determination of the position of anomalous sources. It is therefore 


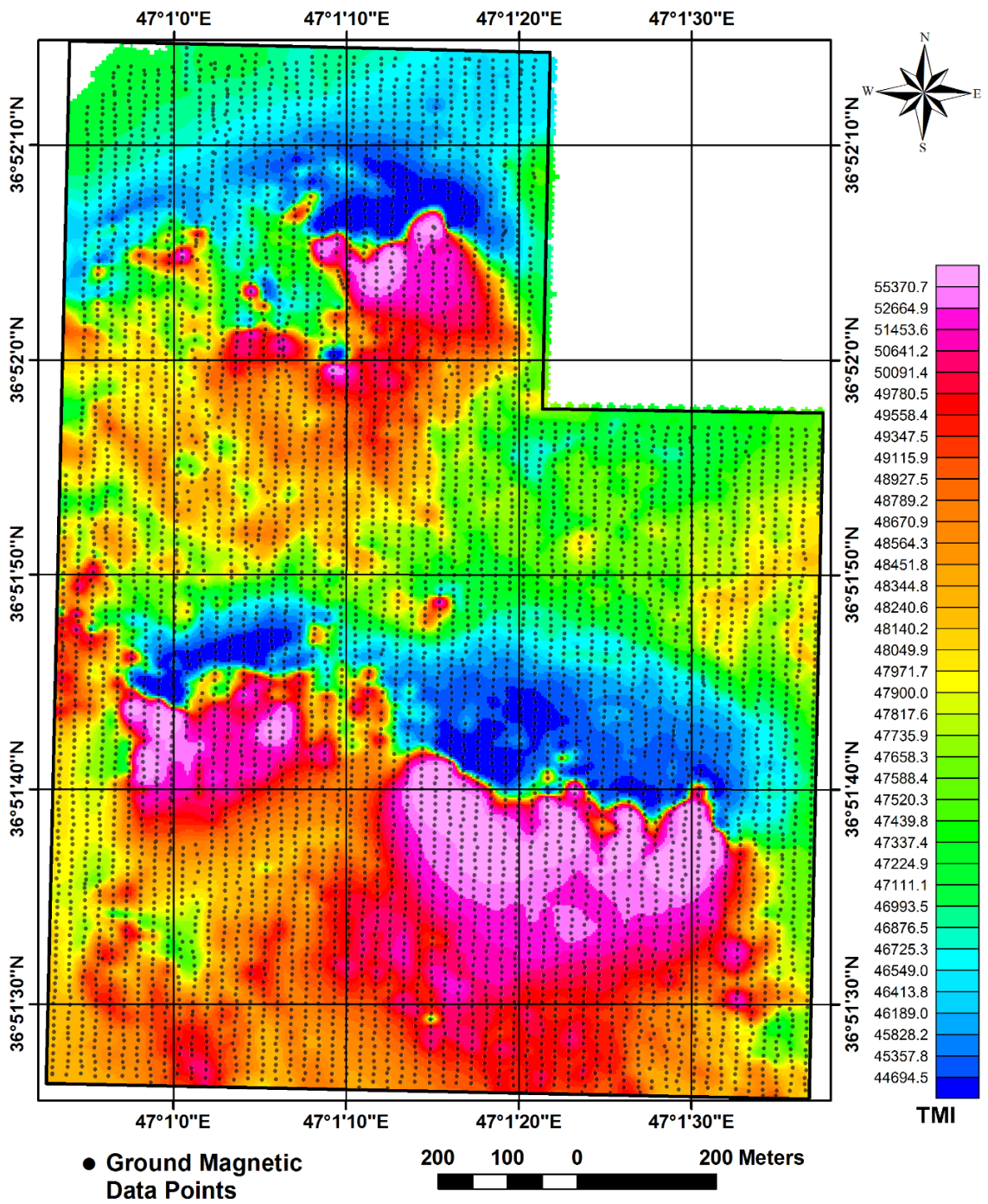

Figure 2. TMI map of Qoja-Kandi with ground magnetic data points.

understood that the total magnetization direction is equivalent to that of the current-inducing field.

Before applying the methods, the total field anomaly data were converted to RTP using a magnetic inclination of $55.43^{\circ}$ and a declination of $4.93^{\circ}$. RTP anomalies show three obvious magnetic anomalies (two anomalies in the east and west of the south and one anomaly in the north) in the studied area, elongated in an approximate $\mathrm{E}-\mathrm{W}$ direction. The highest class of RTP magnetic anomalies (RTP-MA) based on the reduction-to-the-pole technique is $>55370.7 \mathrm{nT}$ with 24941.79 square metres in area. Also, RTP anomalies were classified to different populations based on this method, as illustrated in Fig. 3. Based on this method, drilling points' determination with the RTP technique was complicated.

\subsection{Application of $C-A$ modelling on the RTP-MA}

Multifractal models are utilized to quantify patterns such as geophysical data. Fractal and multifractal modelling are widely applied to distinguish the different mineralized zones (Cheng, 2007). Multifractal theory could be interpreted as a theoretical framework that explains the power-law relationships between areas enclosing concentrations below a given threshold value and the actual concentration itself. To demonstrate and prove that data distribution has a multifractal nature, an extensive computation is required (Halsey et al., 1986). This method has several constraints, especially when the boundary effects on irregular geometrical data sets are involved (Agterberg et al., 1996; Goncalves, 2001; Cheng, 2007; Xie et al., 2010). Multifractal modelling in geophysical and geochemical exploration helps to find exploration targets and mineralization potentials in dif- 


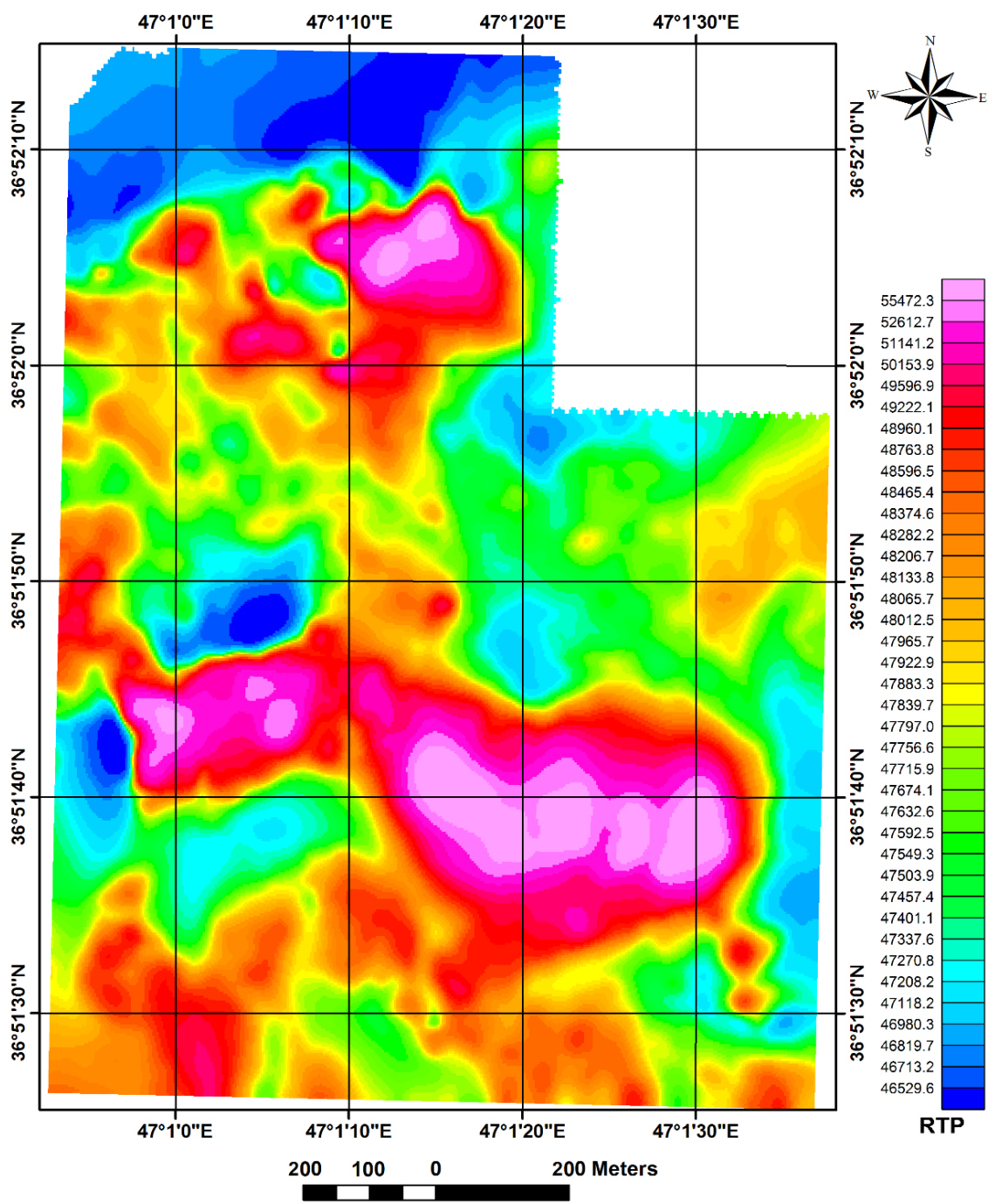

Figure 3. RTP map of Qoja-Kandi based on the reduction-to-the-pole technique.

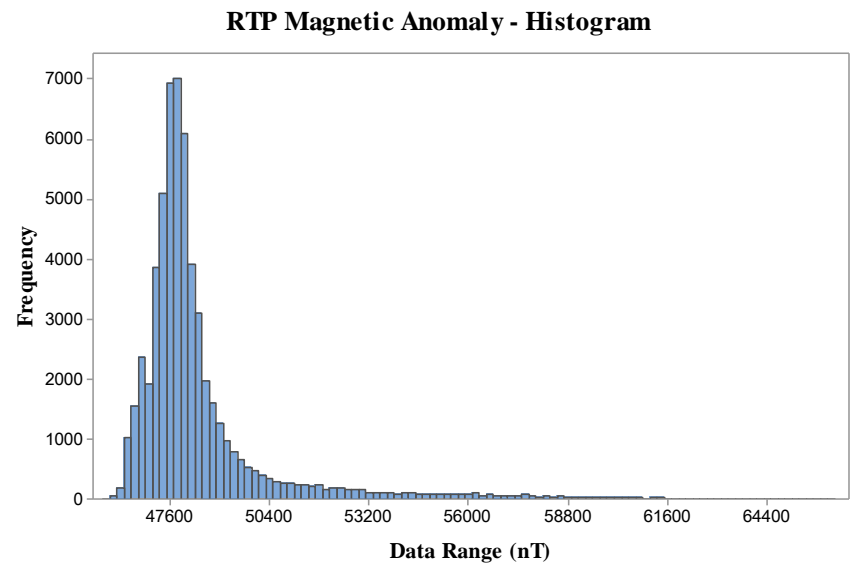

Figure 4. Histogram of RTP-MA data in Qoja-Kandi.

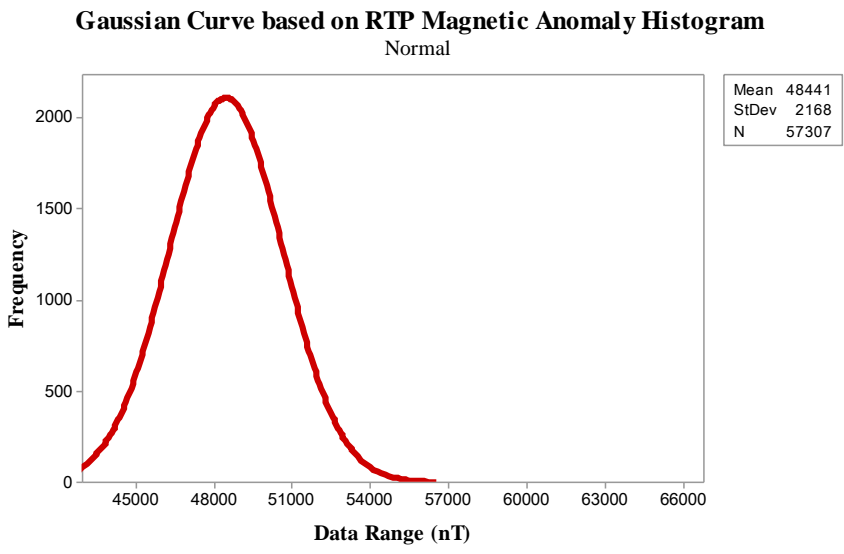

Figure 5. Gaussian curve based on the RTP magnetic anomaly histogram in Qoja-Kandi. 


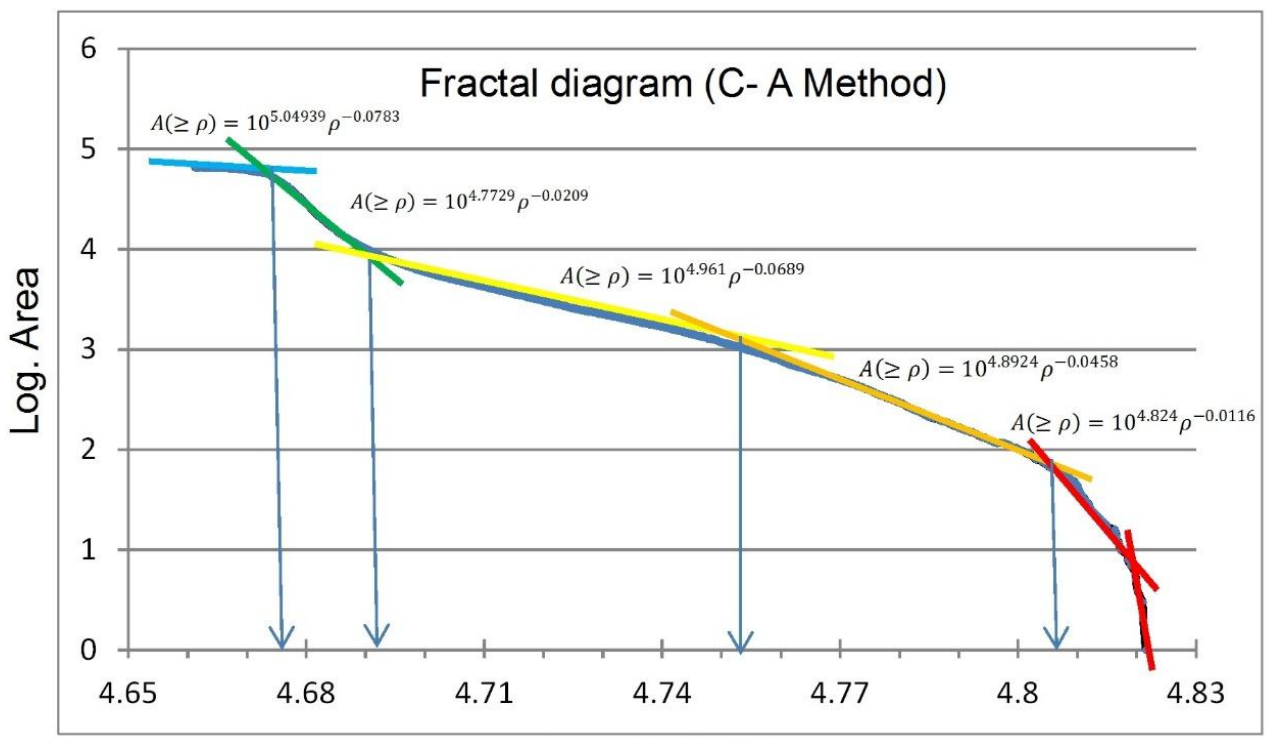

Log. RTP(nT)

Figure 6. Log-log plot for RTP-MA data in Qoja-Kandi.

ferent types of deposits (Yao and Cheng, 2011). The $C-A$ method seems to be equally applicable to all cases, which means that geophysical distributions mostly satisfy the properties of a multifractal function. There is some evidence that geophysical and geochemical data distributions have fractal behaviour in nature, e.g. Bolviken et al. (1992), Turcotte (1997), Goncalves (2001), Gettings (2005) and Li and Cheng (2006). This theory improves the development of an alternative interpretation validation and useful methods to be applied to geophysical distribution analysis.

In this study, 57307 transformed RTP data were processed for identification of magnetic anomalies. Statistical results reveal that the RTP-MA mean value is $48441 \mathrm{nT}$, as depicted in Fig. 4, and the RTP-MA domain shows a wide range. $C-A$ modelling overcomes the distortion effects of outliers on the traditional techniques and makes it unnecessary to determine whether the concentration data are drawn from a normal (i.e. Gaussian) distribution or log-normal distribution, and this advances the analysis resolution of anomalies (Fig. 5). The RTP-MA distribution map was generated with the minimum curvature method. The estimated RTP-MA model in terms of RTP data values was intended to build the $C-A \log -\log$ plot for RTP-MA. Based on the linear segments and breakpoints log-log plot, as shown in Fig. 6, geophysical population were divided. RTP threshold values are 45 383, 47424.2 , 49 493.7, 56493.7 and 635331.1, which are very low, low, moderate, high and very high intensity anomaly threshold values, respectively, as illustrated in Table 1. Pairs of estimated exponents and the corresponding optimum thresholds for RTP-MA are presented in Table 2. The thresholds delineate anomalous areas. Comparison of the areas above and below the threshold of $6022 \mathrm{nT}$ on the contour map (Fig. 3)

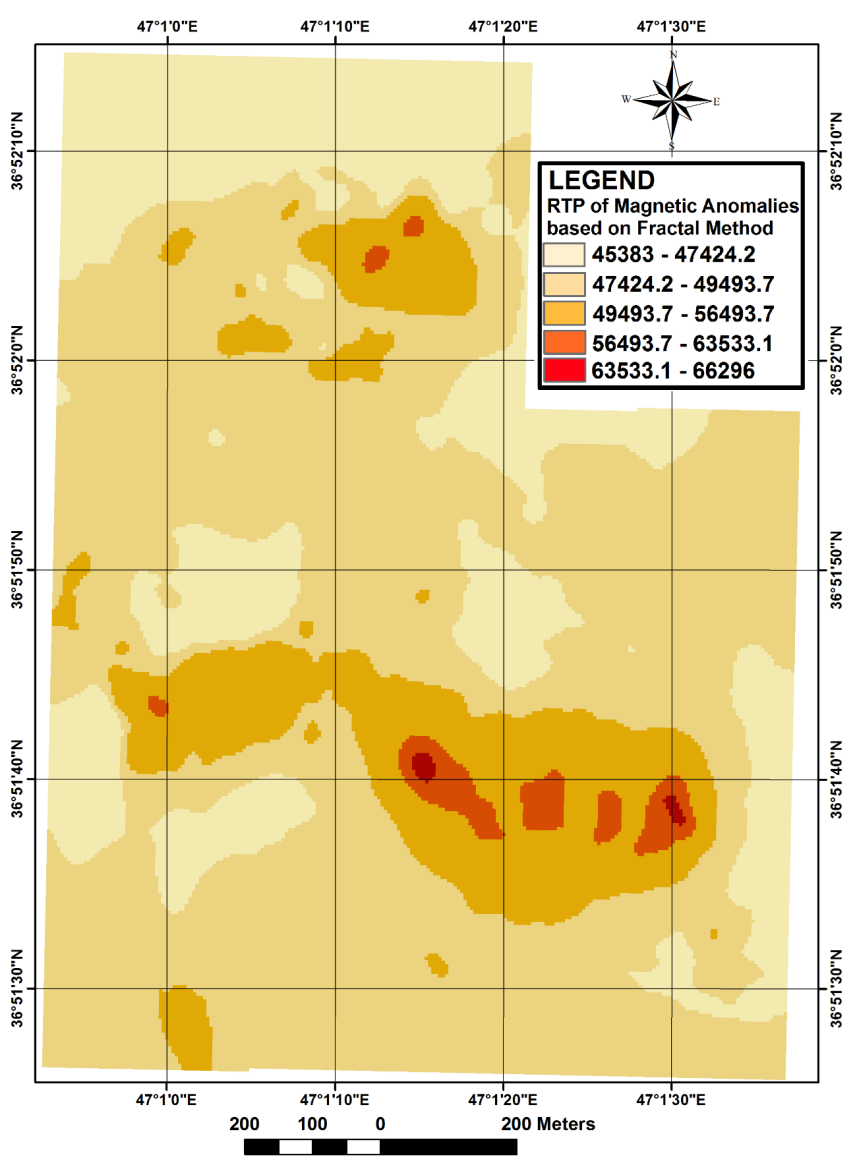

Figure 7. RTP map of Qoja-Kandi based on the $C-A$ method. 


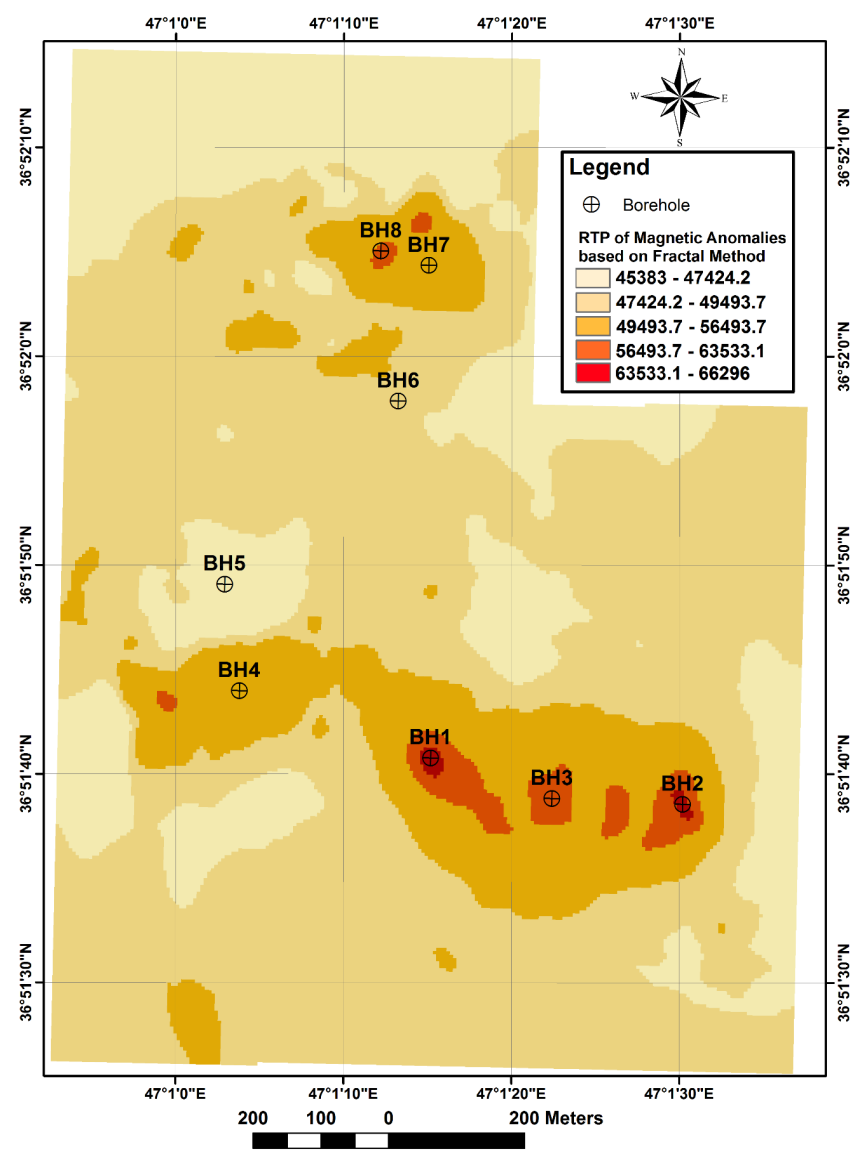

Figure 8. RTP map of Qoja-Kandi based on the $C-A$ method with drilled boreholes.

with the RTP map shows significant spatial correlation between the areas with RTP-MA concentrations above $6022 \mathrm{nT}$. These geophysical populations were determined based on the breakpoints in the $\log -\log$ plot. Actually, the length of the tangent demonstrates the extents of geophysical populations in the fractal model. It is mentioned that the number of the population in the fractal model could be more or less than 5 , but actually the extent of the last class population is not highly dependent on the number of the population in the fractal model. Hence, there are five populations for RTPMA, which illustrates that the fifth class of RTP-MA based on the fractal method is $>63533.1 \mathrm{nT}$, with very high priority for drilling. Consequently, the locations of RTP-MA (two anomalies) based on the fractal method are situated in the east of the southern part of the area, as depicted in Fig. 7.

\section{Control with borehole data}

A method of investigating subsurface geology is, of course, drilling boreholes. For a more accurate result about identification of magnetic anomalies, the results of $C-A$ modelling on the RTP-MA are compared with borehole data (Table 3).
There are eight drilled boreholes in this area that are used for identification of magnetic anomalies obtained from boreholes (Fig. 8). The drilled boreholes were analysed and studied by geologists. Hence, the ranges of magnetite ores in each borehole were obtained and documented as the log report in Table 2. The accepted lower limit for the ore length is the grade $20 \% \mathrm{Fe}$ total.

RTP transformed data based on ground magnetic anomaly data collected from $C-A$ moderate anomalies in the QojaKandi prospecting area show a magnetic susceptibility concentration between 63533.1 and $66296 \mathrm{nT}$, with $1957.64 \mathrm{~m}^{2}$ in area. This study shows that the areas with very high priority obtained by the $C-A$ method have a magnetite concentration with the appropriate thickness. This point is significant that boreholes 1 and 2 were drilled in the mentioned places and confirmed the results of the $C-A$ model (Fig. 9) for increasing the resolution of drilling point determination and decreasing the drilling risk. Figure 8 shows the 3-D RTP map of Qoja-Kandi based on the $C-A$ method with pictures from magnetite zones in the surface of drilled boreholes 1 and 2, in addition to the mentioned borehole log plots. It is necessary to mention that the TERRA satellite has a back-looking telescope with a resolution of $15 \mathrm{~m}$ in the VNIR that matches with the wavelength of the band 3 that is used to extract 3-D information for the provided Fig. 9.

The results confirmed that there is an affirmative correlation between anomalies derived via the $C-A$ method and the $\log$ report of boreholes. Furthermore, the ratio of the ore length and total core length is calculated in Table 3. The number of this ratio is between ranges of 0 to 1 . Whenever this number is larger and close to 1 , the resolution of the drilling point determination increases and the drilling risk decreases. The results show a positive correlation between the ratio of the ore and total core column, and priority areas for the drilling column. Based on this study, anomalies associated with andesite units host iron mineralization. Also, there is no mineralization in other geological units such as limestones and conglomerates in the northwest of the studied area. It should be noted that magnetite ores have outcrops in andesite units (Fig. 9).

\section{Conclusions}

Separation of magnetic anomalies using a combination of the RTP technique and $C-A$ fractal modelling has been used in the Qoja-Kandi prospecting area as a new geophysical method for increasing the resolution of the drilling points' determination. This study demonstrates that the $C-A$ method utilized for ground magnetic anomaly separation is an appropriate method for geophysical prospecting.

There was a multifractal model for RTP-MA, based on $\log -\log$ plots in the prospecting area. In this paper, RTP anomaly results from the $C-A$ method and the RTP technique were compared. Anomalies resulting from the RTP 


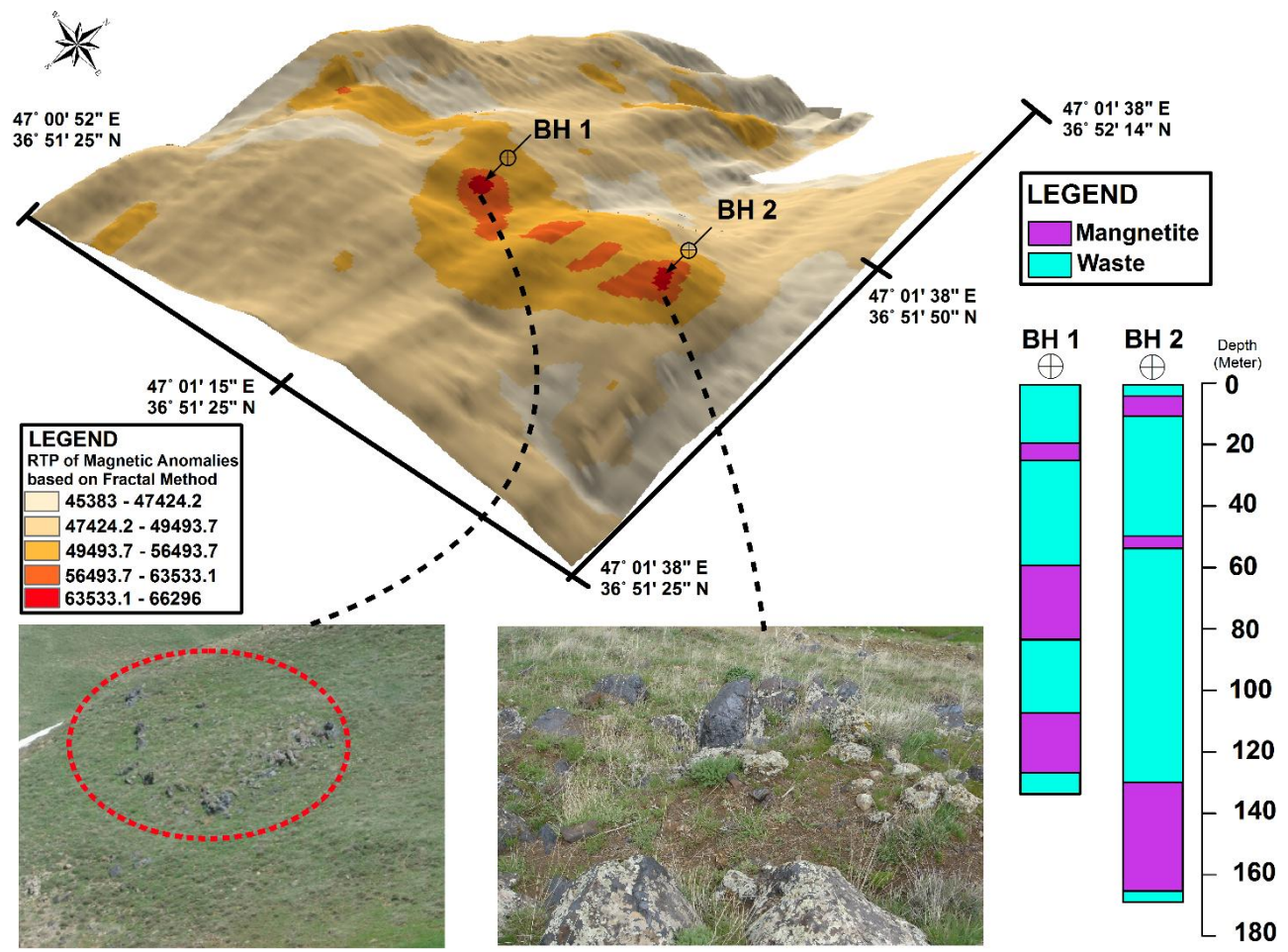

Figure 9. Three-dimensional RTP map of Qoja-Kandi based on the $C-A$ method with pictures from magnetite zones in the surface of drilled boreholes 1 and 2, in addition to the mentioned boreholes' log plots.

Table 3. Log report of boreholes with RTP classification based on the fractal method.

\begin{tabular}{|c|c|c|c|c|c|c|}
\hline \multirow[t]{2}{*}{$\begin{array}{l}\text { Borehole } \\
\text { ID }\end{array}$} & \multirow[t]{2}{*}{$\begin{array}{r}\text { Total core } \\
(\mathrm{m})\end{array}$} & \multirow[t]{2}{*}{$\begin{array}{r}\text { Magnetite thickness }(\mathrm{m}) \\
\text { in total core (grades greater } \\
\text { than } 20 \% \text { Fe total) }\end{array}$} & \multirow[t]{2}{*}{$\begin{array}{r}\text { Ore/total } \\
\text { core }\end{array}$} & \multicolumn{2}{|c|}{$\begin{array}{l}\text { Magnetite } \\
\text { range } \\
(\mathrm{m})\end{array}$} & \multirow[t]{2}{*}{$\begin{array}{l}\text { Priority areas } \\
\text { for drilling }\end{array}$} \\
\hline & & & & From & To & \\
\hline BH1 & 136.5 & 52.4 & 0.38 & $\begin{array}{r}19.3 \\
60.7 \\
109.4\end{array}$ & $\begin{array}{r}25.2 \\
85.2 \\
131.4\end{array}$ & Very high \\
\hline $\mathrm{BH} 2$ & 171.2 & 47.2 & 0.27 & $\begin{array}{r}4 \\
50.2 \\
130.6\end{array}$ & $\begin{array}{r}12.2 \\
53.5 \\
166.3\end{array}$ & Very high \\
\hline $\mathrm{BH} 3$ & 151.2 & 32 & 0.21 & $\begin{array}{r}80 \\
112\end{array}$ & $\begin{array}{l}102 \\
122\end{array}$ & High \\
\hline BH4 & 106 & 12.5 & 0.11 & $\begin{array}{l}44 \\
81\end{array}$ & $\begin{array}{r}48 \\
89.5\end{array}$ & Moderate \\
\hline BH5 & 58.9 & 0 & 0 & - & - & Very low \\
\hline BH6 & 136.5 & 3 & 0.02 & 69 & 72 & Low \\
\hline BH7 & 172 & 14 & 0.08 & $\begin{array}{r}44 \\
61.5 \\
156\end{array}$ & $\begin{array}{r}47 \\
63.5 \\
164\end{array}$ & Moderate \\
\hline BH8 & 157 & 29 & 0.18 & $\begin{array}{r}70 \\
133\end{array}$ & $\begin{array}{r}90 \\
142\end{array}$ & High \\
\hline
\end{tabular}


technique show huge anomalies in three parts, but the $C$ $A$ method shows two small anomalies. RTP anomalies based on the RTP technique are similar to anomalies from the $C-$ $A$ method because of normal distribution in the Qoja-Kandi area. According to correlation between geological particulars and RTP anomalies obtained by the $C-A$ method, andesite units host the anomalies in the studied area.

There is an appropriate correlation between the calculated anomalous threshold values and ore thicknesses in total cores. Also, the ratio of the ore length and total core length is related to an anomalous threshold, calculated with the $C$ $A$ method. Based on the RTP technique, three anomalies were identified (two RTP anomalies in the east and west of the southern part of the area and one anomaly in the northern part). Also, according to the $C-A$ method, two small anomalies are situated in the east of the southern part of the prospecting area, with very high priority for drilling. Boreholes 1 and 2 were drilled in the mentioned places and confirmed the results of the $C-A$ model for increasing the resolution of drilling point determination and decreasing the drilling risk.

Hence, studying geophysical magnetic anomalies with the $C-A$ method can be a proper way for geophysicists to find targets with enriched magnetic elements. Also, applying $C-$ $A \log -\log$ can increase the resolution of the drilling point determination and decrease the drilling risk.

Acknowledgements. The authors would like to thank M. Sahandi for providing data. Also the authors would like to thank A. G. Hunt for his helpful suggestions for improving this paper.

Edited by: A. G. Hunt

\section{References}

Abedi, M., Torabi, S. A., and Norouzi, G. H.: Application of fuzzy AHP method to integrate geophysical data in a prospect scale, a case study: Seridune copper deposit, Boll. Geofisica Teorica Appl., 54, 145-164, 2013.

Agterberg, F. P., Cheng, Q., Brown, A., and Good, D.: Multifractal modeling of fractures in the Lac du Bonnet batholith, Manitoba, Comput. Geosci., 22, 497-507, 1996.

Arian, M.: Physiographic-Tectonic Zoning of Iran's Sedimentary Basins, Open J. Geol., 3, 169-177, 2013.

Baranov, V.: A new method for interpretation of aeromagnetic maps; pseudo-gravimetric anomalies, Geophysics, 22, 359-382, 1957.

Baranov, V. and Naudy, H.: Numerical calculation of the formula of reduction to the magnetic pole, Geophysics, 29, 67-79, 1964.

Bolviken, B., Stokke, P. R., Feder, J., and Jossang, T.: The fractal nature of geochemical landscapes, J. Geochem. Explor., 43, 91109, 1992.
Cheng, Q.: Spatial and scaling modelling for geochemical anomaly separation, J. Geochem. Explor., 65, 175-194, 1999.

Cheng, Q., Agterberg, F. P., and Ballantyne, S. B.: The separartion of geochemical anomalies from background by fractal methods, J. Geochem. Explor., 51, 109-130, 1994.

Cheng, Qiuming: Multifractal imaging filtering and decomposition methods in space, Fourier frequency, and eigen domains, Nonlin. Processes Geophys., 14, 293-303, doi:10.5194/npg-14-2932007, 2007.

Dimri, V. P.: Fractal Behavior of the Earth System, The Netherlands, Springer, 208 pp., 2005.

Gettings, M. E.: Multifractal magnetic susceptibility distribution models of hydrothermally altered rocks in the Needle Creek Igneous Center of the Absaroka Mountains, Wyoming, Nonlin. Processes Geophys., 12, 587-601, doi:10.5194/npg-12-5872005, 2005.

Goncalves, M. A., Mateus, A., and Oliveira, V.: Geochemical anomaly separation by multifractal modeling, J. Geochem. Explor., 72, 91-114, 2001.

Halsey, T. C., Jensen, M. H., Kadanoff, L. P., Procaccia, I., and Shraiman, B. I.: Fractal measures and their singularities: The characterization of strange sets. Phys. Rev. A, 33, 1141-1151, 1986.

Hassan-Nezhad, A. A. and Moore, F.: A stable isotope and fluid inclusion study of the Qaleh-Zari $\mathrm{Cu}-\mathrm{Au}-\mathrm{Ag}$ deposit, Khorasan Province, Iran, J. Asian Earth Sci., 27, 805-818, 2006.

Korvin, G.: Fractal Models in the Earth Science, Elsevier, Amsterdam, 396 pp., 1992.

Li, Q. and Cheng, Q.: VisualAnomaly: A GIS-based multifractal method for geochemical and geophysical anomaly separation inWalsh domain, Comput. Geosci., 32, 663-672, 2006.

Lima, A., De Vivo, B., Cicchella, D., Cortini, M., and Albanese, S.: Multifractal IDWinterpolation and fractal filtering method in environmental studies: an application on regional stream sediments of (Italy), Campania region, Appl. Geochem., 18, 1853-1865, 2003.

Mandelbrot, B. B.: The Fractal Geometry of Nature, W. H. Freeman, San Fransisco, 468 pp., 1983.

Shen, W., Fang, C., and Zhang, D.: Fractal and Chaos Research of Geomagnetic Polarity Reversal, Earth Sci. Front., 16, 201-206, 2009.

Turcotte, D. L.: Fractals and Chaos in Geology and Geophysics, Cambridge University Press, Cambridge, 398 pp., 1997.

Turcotte, D. L.: Fractals in geology and geophysics, Pure Appl. Geophys., 131, 171-196, 1989.

Turcotte, D. L.: The relationship of fractals in geophysics to "the new science", Chaos, Soliton. Fract., 19, 255-258, 2004.

Xie, S., Cheng, Q., Zhang, S., and Huang, K.: Assessing microstructures of pyrrhotites in basalts by multifractal analysis, Nonlin. Processes Geophys., 17, 319-327, doi:10.5194/npg-17-3192010, 2010.

Yao, L. and Cheng, Q.: Multi-scale interactions of geological processes during mineralization: cascade dynamics model and multifractal simulation, Nonlin. Processes Geophys., 18, 161-170, doi:10.5194/npg-18-161-2011, 2011. 